\title{
Tracheal Rupture: A Rare Complication of Endotracheal Intubation
}

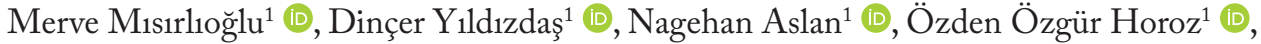 \\ Önder Özden ${ }^{2}$ (1) \\ Case Report $>{ }^{1}$ Department of Pediatrics, Division of Pediatric Intensive Care, Çukurova University School of Medicine, Adana, Turkey \\ ${ }^{2}$ Department of Pediatric Surgery, Çukurova University School of Medicine, Adana, Turkey
}

Abstract

ORCID IDs of the authors: M.M. 0000-0002-9554-841X; D.Y. 0000-0003-0739-5108; N.A. 0000-0002-6140-8873; O..0.H. 0000-0001-7590-650X 0.0. 0000-0001-5683-204X.

Cite this article as: Mısırlıoğlu M, Yıldızdaş D, Aslan N, Horoz Ö̈, Özden Ö. Tracheal Rupture: A Rare Complication of Endotracheal Intubation. Turk Arch Otorhinolaryngol 2019; 57(3): 154-6.

This study was presented at the $15^{\text {th }}$ Pediatric Emergency Medicine and Intensive Care Congress, October 17-20, 2018, Muğla, Turkey.

\section{Corresponding Author:}

Merve Mısırlığlu; mervemisirlioglu@gmail.com

Received Date: 26.02.2019

Accepted Date: 24.05.2019

Content of this journal is licensed under a Creative Commons Attribution 4.0 International License. Available online at www.turkarchotolaryngol.net
Clinicians can encounter various complications after endotracheal intubation as a result of patient anatomy, difficult intubation, and time and number of interventions performed. A life-threatening complication of intubation is iatrogenic tracheal rupture that leads to pulmonary air leak syndromes. In this case report, we present a 10 -month-old patient who presented to the healthcare center with cyanosis and cough after foreign body aspiration and underwent endotracheal intubation for hypoxia. In our report, we aim to draw attention to tracheal rupture, a complication that was identified in bronchoscopy and found to be associated with repeated interventions and stylet use.

Keywords: Child, endotracheal intubation, complication, tracheal rupture

\section{Introduction}

Iatrogenic tracheal injuries can occur following thoracic surgery and endotracheal interventions. The most frequent cause of iatrogenic complications is intubation (1). Tracheobronchial injury is a rare, critical complication that can occur following endotracheal intubation. Insufficient experience of the practitioner, hence repeated unsuccessful intubation attempts, intervention before deflating the endotracheal tube balloon cuff or excessive inflation of the balloon after application, and use of a stylet for intubation increase the risk of complications (2). Though rare, there are tracheal rupture cases in the literature that are associated with endotracheal intubation in the pediatric age group (3, 4). This study attempts to draw attention to one such vital complication, in review of the literature, presenting a case in which iatrogenic tracheal rupture developed following an intubation performed in a healthcare center for respiratory distress after foreign body aspiration.

\section{Case Presentation}

A 10-month-old female patient who had been taken to a healthcare center for foreign body as- piration was transferred to our hospital for intubation and bronchoscopy. The initial examination of the child in the emergency room revealed tachypnea, retractions, and tachycardia. The patient had widespread subcutaneous emphysema and an oxygen saturation of $80-85 \%$ despite positive pressure ventilation. Posteroanterior (PA) chest radiography demonstrated pneumomediastinum and subcutaneous emphysema (Figure 1). The pediatric surgeons performed rigid bronchoscopy to extract the foreign body. During the procedure, a peanut particle was removed from the right main bronchus, and an approximately four $\mathrm{cm}$ tracheal rupture was observed starting distal to the vocal cords and extending towards the carina (Figure 2). Right thoracotomy was applied, and the tracheal rupture was treated with primary suturing by the pediatric surgeons. No tracheoesophageal fistula was observed following the administration of methylene blue. The intubated patient was taken to the pediatric intensive care unit following the operation. It was consequently learned from the detailed history obtained from the family and the healthcare center that the patient had sudden cyanosis while eating a peanut on the previous day; 
she was taken to an emergency room of a health center due to coughing, asphyxiation, and cyanosis 12 hours after the incident. Because she was not taken to a hospital immediately, hypoxia developed, and endotracheal intubation was planned. But the patient was intubated with difficulty, repeated intubations had

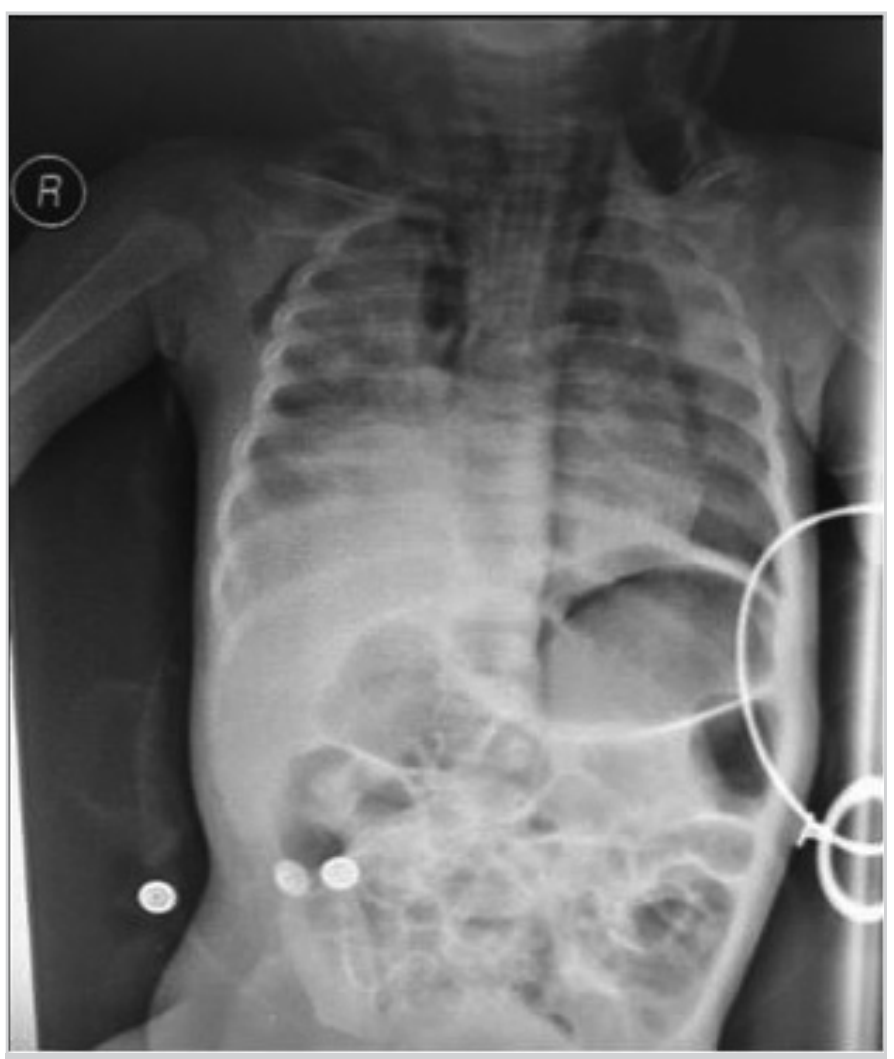

Figure 1. Subcutaneous emphysema and pneumomediastinum on pre-operative posteroanterior chest radiograph

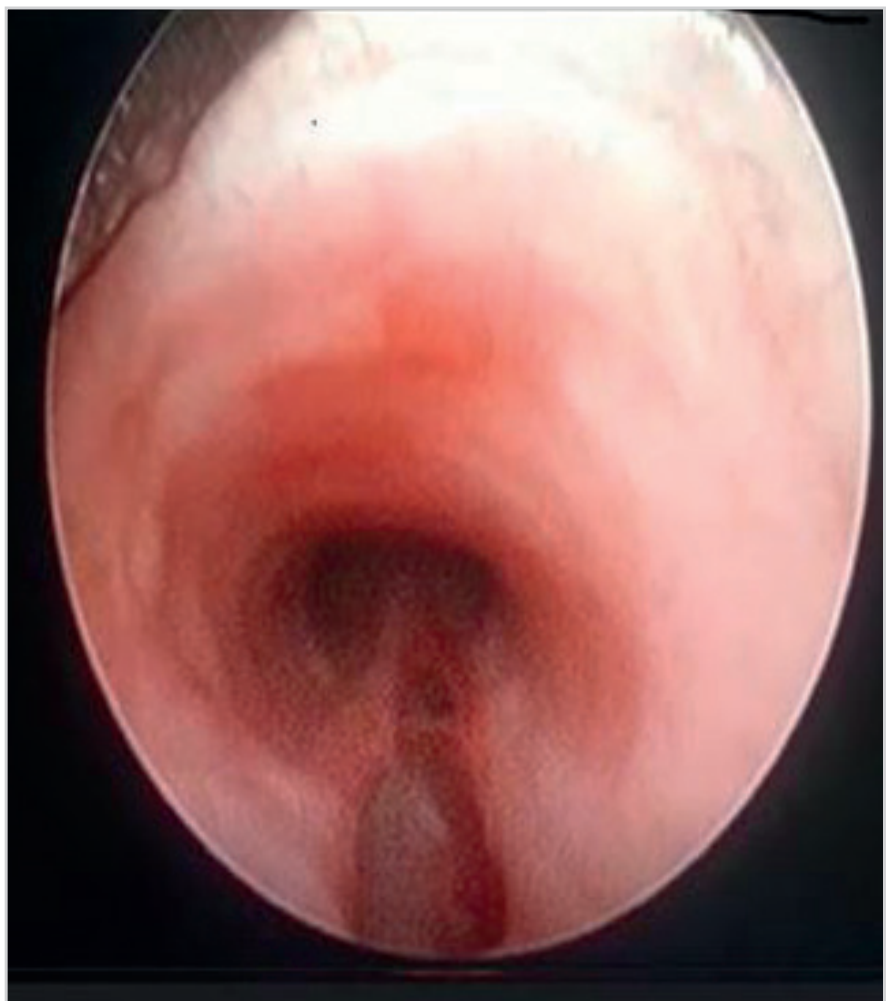

Figure 2. Rigid bronchoscopy image of tracheal rupture been applied with an endotracheal tube and stylet. Intubation follow-up was scheduled until mucosal healing and epithelization could be confirmed following tracheal treatment. Having been started on sedation, analgesia and myorelaxant medications, the patient was placed on a mechanical ventilator. Empiric vancomycin and meropenem antibiotherapy was started for mediastinitis. Sedation was stopped on the $5^{\text {th }}$ postoperative day, and the patient was extubated. Her vocal cord movements were normal in control bronchoscopy. Written informed consent was obtained for this case report from the parents of the patient.

\section{Discussion}

Tracheal rupture is a condition related to blunt trauma or iatrogenic intervention; it requires prompt diagnosis and treatment and can be fatal if left untreated because of air leakage and its complications (5). In tracheal rupture, the patient presents with respiratory distress, subcutaneous emphysema, pneumothorax, and pneumomediastinum. Thoracic surgery and endotracheal interventions are examples to the causes of iatrogenic tracheal rupture.

Cases of tracheal rupture reported after endotracheal intubation are more frequent in adult patients; the incidence ranges between $0.04 \%$ and $0.12 \%$ (6). Pediatric cases are rare $(1,3,5)$. In the literature, there is a case reported about a 14-year-old patient who had tracheal rupture due to endotracheal intubation. The patient had been intubated due to impaired consciousness as a result of butane inhalation, had a right pneumothorax, and tracheal rupture was found on thoracic computed tomography (CT). The patient was not treated surgically but with a conservative approach and extubated on the $5^{\text {th }}$ day (3). In a series of eight cases with traumatic tracheal damage whose ages varied from two to 15 , tracheal damage was reported to be due to endotracheal intubation in six of the patients. The patients were not taken to surgery but treated with a conservative approach, and spontaneous healing was achieved. Tracheal stenosis developed in five of the patients at different levels and one of these cases necessitated tracheotomy (4).

In order to prevent tracheal injuries due to intubation, endotracheal intubation should be performed in a suitable position using a blade and endotracheal tube with the correct dimensions and by providing sedation, analgesia, and when required, myorelaxants in accordance with the rapid sequence intubation steps (7). Failure to visualize the larynx during this process and repeated unsuccessful intubation attempts with a stylet both increase the risk of airway trauma (6). The tip of the stylet placed within the endotracheal tube should be positioned in a way to prevent it from sticking out, and the stylet should be removed after the endotracheal tube passes through the vocal cords to minimize adverse conditions that can arise from stylet utilization (8). We believe that repeated intubation attempts, use of a stylet and sudden, excessive inflation of the endotracheal tube cuff caused the tracheal rupture in our case.

When diagnosis and treatment are delayed, tracheal rupture can cause emphysema, pneumothorax, pneumomediastinum and mediastinitis, and has high mortality and morbidity rates. 
Bronchoscopy should be used to evaluate the location, the size and the depth of the damaged area in such cases (9). Emergent surgery used to be the preferred treatment approach although conservative approaches are utilized today. Conservative treatment can be applied in patients with a lesion size smaller than two $\mathrm{cm}$ above the tube cuff who are clinically stable. Surgical treatment is recommended if the lesion is larger than two $\mathrm{cm}(7$, 10). A conservative approach was used in all the reported pediatric cases. Our case, however, had a 4-cm tracheal rupture, and primary suturing had to be applied by thoracotomy.

\section{Conclusion}

Tracheobronchial injuries should always be suspected in cases of non-healing, subcutaneous emphysema, pneumomediastinum and pneumothorax development following endotracheal intubation. We believe that application of rapid sequence intubation steps with an experienced team and proper equipment is quite important to minimize the complications which may arise after intubation.

Informed Consent: Written informed consent was obtained from the parents of the patient.

Peer-review: Externally peer-reviewed.

Author Contributions: Concept - M.M., D.Y.; Design - M.M., N.A.; Supervision - M.M.; Resource - Ö.Ö.; Materials - M.M., Ö.Ö.; Data Collection and/or Processing - M.M., Ö.Ö.H.; Analysis and/or Interpretation - M.M., N.A.; Literature Search - M.M., N.A.; Writing - M.M., N.A.; Critical Reviews - D.Y., Ö.Ö.H.

Conflict of Interest: The authors have no conflicts of interest to declare.
Financial Disclosure: The authors declared that this study has received no financial support.

\section{References}

1. Hofmann HS, Rettig G, Radke J, Neef H, Silber RE. Iatrogenic ruptures of the tracheobronchial tree. Eur J Cardiothorac Surg 2002; 21: 649-52. [CrossRef]

2. Sternfeld D, Wright $\mathrm{S}$. Tracheal rupture and the creation of a false passage after emergency intubation. Ann Emerg Med 2003; 42: 88-92. [CrossRef]

3. Paksu MS, Kilinc AA, Asilioglu N, Gunaydin M, Aydin T, Guzel A. Iatrogenic tracheal rupture in a child: Case study and review of literature. Pediatr Emerg Care 2013; 29: 934-8. [CrossRef]

4. Wood JW, Thornton B, Brown CS, McLevy JD, Thompson JW. Traumatic tracheal injury in children: A case series supporting conservative management. Int J Pediatr Otorhinolaryngol 2015; 79: 716-20. [CrossRef]

5. Altuntaş B, Aydın Y, Eroğlu A. Tips and tricks in tracheobronchial perforations. Turk Gogus Kalp Dama 2016; 24: 514-21. [CrossRef]

6. Borasio P, Ardissone F, Chimapo G. Post-intubation tracheal rupture. A report on ten cases. Eur J Cardiothorac Surg 1997; 12: 98-100. [CrossRef]

7. Baran B, Borazan H, Yosunkaya A. Kardiyak arrest sonrası pnömomediastinum. Anestezi Dergisi 2009; 17: 98-100.

8. Tezel C, Okur E, Baysungur V. Iatrogenic tracheal rupture during intubation with a double-lumen tube. Thorac Cardiovasc Surg 2010; 58: 54-6. [CrossRef]

9. Lim H, Kim JH, Kim D, Lee J, Son JS, Kim DC, et al. Tracheal rupture after endotracheal intubation - A report of three cases. Korean J Anesthesiol 2012; 62: 277-80. [CrossRef]

10. Cunningham LC, Jatana KR, Grischkan JM. Conservative management of iatrogenic membranous tracheal wall injury. JAMA Otolaryngol Head Neck Surg 2013; 139: 405-10. [CrossRef] 